Canadian

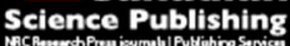

Applied Physiology, Nutrition, and Metabolism Physiologie appliquée, nutrition et métabolisme

\title{
Acute upregulation of PGC-1a mRNA correlates with training-induced increases in SDH activity in human skeletal muscle
}

\begin{tabular}{|r|l|}
\hline Journal: & Applied Physiology, Nutrition, and Metabolism \\
\hline Manuscript ID & apnm-2016-0463.R1 \\
\hline Manuscript Type: & Article \\
\hline Date Submitted by the Author: & $24-N o v-2016$ \\
\hline Keyword: List of Authors: & $\begin{array}{l}\text { Bonafiglia, Jacob; Queen's University, School of Kinesiology and Health } \\
\text { Studies } \\
\text { Edgett, Brittany; Queen's University, School of Kinesiology and Health } \\
\text { Studies } \\
\text { Baechler, Brittany; University of Waterloo, Department of Kinesiology } \\
\text { Nelms, Matthew; Queen's University, School of Kinesiology and Health } \\
\text { Studies } \\
\text { Simpson, Craig; Queen's University, Department of Emergency Medicine } \\
\text { Quadrilatero, Joe; University of Waterloo, Department of Kinesiology } \\
\text { Gurd, Brendon J.; Queens University, }\end{array}$ \\
\hline Segfa, Capillary Density, Sprint Interval Training, Individual Responses, \\
\hline
\end{tabular}


Acute upregulation of PGC-1 $\alpha$ mRNA correlates with training-induced increases in SDH activity in human skeletal muscle

Jacob T. Bonafiglia ${ }^{1}$, Brittany A. Edgett ${ }^{1}$, Brittany L. Baechler ${ }^{3}$, Matthew W. Nelms ${ }^{1}$, Craig A. Simpson $^{2}$, Joe Quadrilatero ${ }^{3}$, and Brendon J. Gurd ${ }^{1}$

\footnotetext{
${ }^{1}$ School of Kinesiology and Health Studies, ${ }^{2}$ Department of Emergency Medicine, Queen's University, Kingston, Ontario, K7L 3N6, Canada; ${ }^{3}$ Department of Kinesiology, University of Waterloo, Waterloo, Ontario, N2L 3G1, Canada
}

J. Bonafiglia:0jtb1@queensu.ca

B. Edgett: b.edgett@queensu.ca

B. Baechler: brittany.baechler@uwaterloo.ca

M. Nelms:m.nelms@queensu.ca

C. Simpson: simps1010@gmail.com

J. Quadrilatero: jquadrilatero@uwaterloo.ca

\section{CORRESPONDING AUTHOR:}

Brendon J. Gurd, PhD

Telephone: 613-533-6000 ext.79023

Fax: 613-533-6000

E-mail: gurdb@queensu.ca 


\begin{abstract}
The purpose of the present study was to determine if acute responses in $p g c-1 \alpha$, vegfa, $s d h a$, and gpdl/2 mRNA expression predict their associated chronic skeletal muscle molecular (SDH/GPD activity and substrate storage) and morphological (fibre type composition and capillary density) adaptations following training. Skeletal muscle biopsies were collected from fourteen recreationally active men (age: $22.0 \pm 2.4$ years) before (PRE) and 3 hours after (3HR) the completion of an acute bout of SIT (eight, 20 -second intervals at $\sim 170 \% \mathrm{VO}_{2}$ peak work rate separated by 10 seconds of recovery). Participants then completed 6 weeks of SIT 4 times per week with additional biopsies after 2 (MID) and 6 (POST) weeks of training. Acute increases in pgc-1 $\alpha$ mRNA strongly predicted increases in SDH activity (a marker of oxidative capacity) from PRE and MID to POST (PRE-POST: $r=0.81, \mathrm{r}^{2}=0.65, p<0.01$; MID-POST: $\mathrm{r}=0.79, \mathrm{r}^{2}$ $=0.62, p<0.01)$ and glycogen content from MID to POST $\left(r=0.60, \mathrm{r}^{2}=0.36, p<0.05\right)$. No other significant relationships were found between acute responses in $p g c-1 \alpha$, vegfa, $s d h a$, and gpd1/2 mRNA expression and chronic adaptations to training. These results suggest that acute upregulation of $p g c-1 \alpha$ mRNA relates to the magnitude of subsequent training-induced increases in oxidative capacity, but not other molecular and morphological chronic skeletal muscle adaptations. Additionally, acute mRNA responses in $p g c-1 \alpha$ correlated with vegfa, but not sdha, suggesting a coordinated upregulation between $p g c-1 \alpha$ and only some of its proposed targets in human skeletal muscle.
\end{abstract}

Key Words: vegfa, SDH activity, capillary density, Individual Responses, sprint interval training 


\section{Introduction}

In human skeletal muscle, acute aerobic exercise stimulates the upregulation of mitochondrial and transcription-regulating genes, while repeated bouts (i.e. exercise training) increase mitochondrial protein content and function (Hood 2001, Flück and Hoppeler 2003, Egan and Zierath 2013) in addition to altering fibre type distribution (Esbjörnsson et al. 1993, Scribbans et al. 2014) and increasing capillary density (Cocks et al. 2013, 2015, Scribbans et al. 2014). The transcriptional coactivator peroxisome proliferator activated receptor gamma coactivator 1 alpha (PGC-1 $\alpha$ ) is implicated in the coordinated activation of nuclear and mitochondrial transcription factors (Lin et al. 2005, Olesen et al. 2010, Safdar et al. 2011, Scarpulla et al. 2012) and appears to play a key role in elevating mRNA expression of many mitochondrial and angiogenic genes, including succinate dehydrogenase protein subunit a (sdha) (Hatazawa et al. 2016), glycerol-3-phosphate dehydrogenase 1 and 2 (gpd1/gpd2) (Patsouris et al. 2004, Krishnan et al. 2009) via peroxisome proliferator-activated receptor alpha (PPAR $\alpha$ ) (Lin et al. 2005), and vascular endothelial growth factor A (vegfa) (Arany et al. 2008, Leick et al. 2009). Following acute exercise, concomitant increases in $p g c-1 \alpha$ and mitochondrial/angiogenic mRNA expression (Pilegaard et al. 2003, Hellsten et al. 2007, Wright et al. 2007, Perry et al. 2010, Iversen et al. 2011) supports a central role for PGC-1 $\alpha$-mediated upregulation of mRNA expression following acute exercise in facilitating subsequent chronic skeletal muscle molecular and morphological adaptations (Hood 2001, Flück and Hoppeler 2003, Flück 2006, Egan and Zierath 2013, Camera et al. 2016).

Despite the apparent acceptance that increases in mRNA expression of $p g c-1 \alpha$ and other mitochondrial/metabolic proteins following acute exercise represents an initial step in the induction of chronic adaptations to exercise training (Hood 2001, Flück and Hoppeler 2003, 
Flück 2006, Egan and Zierath 2013, Camera et al. 2016), few studies have directly examined whether increases in mRNA expression precede increases in skeletal muscle protein content and function. While several studies provide evidence supporting this theory (Serpiello et al. 2012, Stepto et al. 2012, Egan et al. 2013), the work of Perry et al. (2010) most clearly demonstrates the temporal relationship between acute transient increases in mRNA expression, and chronic increases in mitochondrial protein content and maximal enzyme activity. While these findings illustrate a temporal sequence to the adaptive response to exercise, whether the magnitude of an individual participant's induction of gene expression following an acute bout of exercise predicts subsequent molecular and morphological training adaptations in human skeletal muscle is unknown.

Interestingly, considerable individual variability exists in both acute increases in $p g c-1 \alpha$ (Coffey et al. 2009a, 2009b, Wang and Sahlin 2012) and mitochondrial mRNA expression (Mahoney et al. 2005), as well as in chronic training-induced changes in mitochondrial protein content/enzyme activity (Burgomaster et al. 2006, Gibala et al. 2006, Vollaard et al. 2009, McPhee et al. 2011, Granata et al. 2015). While this acute and chronic variance provides a practical framework to investigate skeletal muscle mechanisms underlying individual responses, to our knowledge only inter-individual variance in the chronic response to exercise training has been deliberately examined (Vollaard et al. 2009, McPhee et al. 2011). Importantly, if acute increases in mRNA expression of $p g c-1 \alpha$ and other mitochondrial $/$ metabolic proteins precede subsequent training-induced adaptations within muscle, individuals who demonstrate large increases in mRNA expression after an acute bout of exercise should also demonstrate large adaptive responses to exercise training.

Therefore, the purpose of the present study was to test the hypothesis that the magnitude 
of an individual's acute changes in mRNA expression will predict the magnitude of chronic adaptations to training. Specifically, acute changes in gene expression of $p g c-1 \alpha, s d h a$, gpdl/gpd2, and vegfa were compared to chronic, training-induced adaptations to molecular (SDH/GPD activity and glycogen/IMTG storage) and morphological (fibre type distribution and capillary density) characteristics of skeletal muscle. Acute changes in mRNA expression in response to one bout of sprint interval training (SIT) were compared to chronic adaptations following six weeks of SIT as we have previously demonstrated that this protocol increases SDH/GPD enzyme activity, capillary density, and glycogen/IMTG content at the group level (Scribbans et al. 2014), and induces variability in the individual responses in these skeletal muscle measures (unpublished observations).

\section{Methods}

Fourteen healthy men volunteered to participate in the current study (participant characteristics are presented in Table 1). No participant was involved in more than 3 hours of aerobic exercise (running, jogging, etc.) per week or involved in any structured training program within 6 months prior to study enrollment. Results from this data set, including participant characteristics and group responses in acute $p g c-1 \alpha$ mRNA expression and chronic absolute $\mathrm{VO}_{2}$ peak and SDH activity, have been published previously (Edgett et al. 2016). Each participant attended a preliminary screening session where they were briefed on the study, provided informed consent, and had their height and weight recorded. All experimental procedures performed on human participants were approved by the Health Sciences Human Research Ethics board at Queen's University and conformed to the Declaration of Helsinki. Verbal and written explanation of the experimental protocol and associated risks was provided to all participants prior to obtaining written informed consent. 


\section{Experimental Design}

To determine the relationship between changes in acute mRNA expression and training adaptations, the participants first completed an acute bout of sprint-interval training (SIT) followed by a training program consisting of 4 bouts of SIT per week for 6 weeks. SIT consisted of eight 20 -second intervals separated by 10 seconds of recovery for a total of four-minutes, as described previously (Scribbans et al. 2014). Intervals targeted $170 \%$ of peak work rate from the baseline $\mathrm{VO}_{2}$ peak test for the acute exercise trial and for the first 2 weeks of training, whereas for weeks 3-6 the targeted work rate was increased to $180 \%$. Descriptions of all physiological testing and training, muscle biopsy procedures, and protocols for tissue preparation for subsequent immunofluorescent, histochemical, and real-time PCR analysis have been published previously (Edgett et al. 2016). The protocol outlining the timing of testing and sample collection is presented in Figure 1.

\section{Acute Exercise Visit}

As described previously (Edgett et al. 2016), participants reported to the lab in the morning and were fed breakfast $\sim 72$ hours after the completion of a baseline $\mathrm{VO}_{2}$ peak test and following an overnight fast ( $\sim 12$ hours) after consuming a standardized dinner the night before. One hour after participants completed breakfast, a resting muscle biopsy (PRE) was taken. Immediately following the resting muscle biopsy, participants completed one session of SIT before resting for 3 hours and a second muscle biopsy sample being taken (3HR) from a separate incision site on the same leg as the first biopsy.

\section{Training Intervention}

All participants completed SIT 4 days a week for 6 weeks (week 3 only had two training sessions due to the mid-training (MID) $\mathrm{VO}_{2}$ peak test and biopsy) for a total of 22 training 
sessions. Before each training session, participants performed a warm-up of load-less cycling at a cadence of their choosing for 1 minute. A MID muscle biopsy was taken $\sim 72$ hours (range: 65 72 hours) following 2 weeks ( 8 sessions) of SIT, as per the protocol used for the PRE biopsy. A MID $\mathrm{VO}_{2}$ peak test was completed $\sim 24$ hours following the MID biopsy. Approximately 72 hours (range: 67-74 hours) after the last training session, a post-training (POST) biopsy was taken, following the same protocol as the PRE and MID biopsies, followed by a post-training $\mathrm{VO}_{2}$ peak test $\sim 24$ hours after the POST biopsy.

RNA Extraction and Real-Time PCR

RNA extraction and real-time PCR were performed as we have done previously (Edgett et al. 2013, 2016) on PRE and 3HR samples. Briefly, RNA was extracted using a modified version of the single-step method by guanidinium thiocyanate-phenol-chloroform extraction (Chomcyzynski and Sacchi 1987), and then quantified spectrophotometrically at $260 \mathrm{~nm}$ using a Take3 Plate (Biotek, Winooski, VT, USA). Protein contamination was assessed by measuring absorbance at $280 \mathrm{~nm}$ (samples had an average 260:280 ratio of 1.99 \pm 0.02 , mean $\pm \mathrm{SD})$. One microgram of resulting RNA was reverse transcribed using the QuantiTect Reverse Transcription Kit (Qiagen, Mississauga, ON, Canada). The mRNA expression of $p g c-1 \alpha$, vegfa, sdha, gpd1 and gpd2 were determined by real-time PCR (ABI 7500 Real Time PCR System; Applied Biosystems, Foster City, CA, USA). Primer set efficiencies were determined using real-time PCR with an appropriate cDNA dilution series prior to sample analysis. Average primer setspecific efficiencies (Rasmussen 2001) were $E=2.00 \pm 0.03$. Samples were run in duplicate 25 $\mu \mathrm{L}$ reactions containing: either $50 \mathrm{ng}$ cDNA (pgc-1 $\alpha$ and $g p d 1), 20 \mathrm{ng}$ (vegfa), or $10 \mathrm{ng}$ cDNA (sdha and gpd2) with $0.58 \mu \mathrm{M}$ primers, and GoTaq PCR Master Mix containing SYBR Green (Promega, Madison, WI, USA). Primer sequences are provided in Table 2. All RNA data are 
expressed relative to TATA-binding protein (TBP), which was stable across all states with no difference in the raw $\mathrm{C}_{\mathrm{T}}$ values observed between resting and 3 hours post-exercise (PRE: 22.45 $\pm 0.40,3$ HR: $22.51 \pm 0.31, p=0.621)$.

\section{Immunofluorescent Analysis}

Immunofluorescent analysis of myosin heavy chain isoforms was performed as previously described (Bloemberg and Quadrilatero 2012, Scribbans et al. 2014) using primary antibodies against myosin heavy chain (MHC) I (BA-F8), MHCIIa (SC-71), and MHCIIx (6H1) (Developmental Studies Hybridoma Bank, Iowa City, IA, USA), followed by isotype-specific fluorescent secondary antibodies (Life Technologies, Burlington, ON, CA). This allowed for the identification of type I (blue), type IIA (green), and type IIX (red). Fibre type composition was determined by counting all fibres within a muscle cross-section and expressed as a percentage of the total number of fibres. Additionally, cross-sectional area (CSA) was determined by outlining approximately 40 of each fibre type within a cross-section and measured as squared micrometers $\left(\mu \mathrm{m}^{2}\right)$. Total CSA was calculated as the sum of each fibre type's CSA multiplied by the percentage of those fibres present in the cross section divided by 100 (arbitrary units; AU).

Quantification of capillary density was performed as previously described (Scribbans et al. 2014). Briefly, sections were fixed in 4\% paraformaldehyde for 5 minutes, followed by permeabilization with $0.5 \%$ Triton X-100 for 5 minutes, and then blocked in $10 \%$ goat serum for 30 minutes. Sections were incubated overnight in 5\% goat serum with the appropriate primary antibodies specific for the endothelium (collagen IV) and sarcolemma (dystrophin) (Developmental Studies Hybridoma Bank, Iowa City, IA, USA). After 35 -minute washes in PBS, sections were incubated for 1 hour in 5\% goat serum with the appropriate fluorescent secondary antibodies (Life Technologies, Burlington, ON, CA). Capillary density was 
determined by counting the number of capillaries within 3 separate areas per sample. Capillary density is expressed as the average number of capillaries per millimetre squared (cap/ $\left./ \mathrm{mm}^{2}\right)$.

For all immunofluorescent procedures, sections were mounted with Prolong Gold Antifade Reagent (Life Technologies, Burlington, ON, CA) and imaged the following day. All of these sections were visualized with an Axio Observer Z1 microscope (Carl Zeiss, Jena, TH, DE). Individual images were taken across the entire muscle cross-section and assembled into a composite panoramic image using AxioVision software (Carl Zeiss).

\section{Histochemical Analysis}

As previously described (Bloemberg and Quadrilatero 2012, Scribbans et al. 2014), histochemical staining for SDH and GPD activity was performed as general indicators of oxidative and glycolytic potential, respectively. Additionally, intramusclar triglyceride (IMTG) content was determined with Oil Red O (ORO) staining, whereas glycogen content was determined using the Periodic Acid Schiff (PAS). Images were acquired with a bright field Nikon microscope linked to a PixelLink digital camera. Individual images were taken across the entire muscle cross-section and assembled into a composite panoramic image using Microsoft Image Composite Editor (ICE) (Microsoft, Redmond, WA, USA). Image analysis was performed in Image J by converting color images to 8 - bit, and calculated by subtracting background staining from the mean grey value of individual fibres. All compiled images were matched to fibre type images and $\sim 30$ unblemished fibres (i.e. without marks or holes) of each fibre type were randomly selected and analyzed. Fibre type specific measures for enzyme activity and substrate storage were calculated by averaging the optical density (AU) for all selected fibres within a cross-section. Fibre type specific analysis was conducted for type I and type IIA fibers only as type IIX fibers were not present in each sample. Estimates of total enzyme activity and 
substrate storage were calculated utilizing the following equation:

$$
\text { Total Estimate }(A U)=\frac{\left(O D_{I} \times F T_{I} \times C S A_{I}\right)+\left(O D_{I I A} \times F T_{I I A} \times C S A_{I I A}\right)}{100000}
$$

where OD is the mean optical density, FT is the fibre type composition, and CSA is the mean cross-sectional area of a given fibre type (type I and type IIA) within a muscle cross-section. Statistical Analysis

Statistical analysis of change in gene expression from PRE to $3 \mathrm{HR}$ was performed on linear data using the $2^{-\Delta \mathrm{C}_{\mathrm{T}}}$ method using TATA-binding protein (TBP) as a housekeeping gene (Schmittgen and Livak 2008). This linear data was then compared using a paired Student's $t$-test. A one-way repeated measures ANOVA was used to examine the impact of SIT on $\mathrm{VO}_{2}$ peak, capillary density, and total muscle estimates of SDH and GPD activity, and glycogen and IMTG content, whereas two-way repeated measures ANOVA were used to measure fibre type specific responses (fibre type x time). Any significant interactions or main effects were subsequently analyzed using a Bonferroni post hoc analysis where appropriate. Linear regressions were used to determine whether changes in mRNA expression following acute SIT predicted traininginduced skeletal muscle responses following 2 (PRE-MID) and 6 weeks of SIT (PRE-POST), and any delayed (MID-POST) chronic adaptations. Statistical significance for all measures was set at $p<0.05$ and all data is presented as mean \pm standard deviation (SD).

\section{Results}

Attendance at training sessions was $100 \%$ over the six weeks for all participants but one, who discontinued the study following the $\mathrm{MID} \mathrm{VO}_{2}$ peak test due to unforeseen scheduling conflicts. The total number of samples analyzed for each variable are reported in the corresponding figure captions. A main effect of training on relative and absolute $\mathrm{VO}_{2}$ peak was observed ( $\mathrm{n}=12, p<0.05$; Table 1$)$. Post hoc analysis revealed a significant increase from PRE 
to POST only $(p<0.001)$.

Relationship between responses in acute $m R N A$ expression and training adaptation

Relationships between acute responses in $p g c-1 \alpha$ mRNA expression and the initial (PREMID), delayed (MID-POST), and total (PRE-POST) training-induced adaptations to SIT in capillary density, SDH and GPD activity, glycogen and IMTG content, fibre type composition, and total CSA are presented in Table 3. Relationships between responses in acute $p g c-1 \alpha$ mRNA and chronic SDH activity are also presented in Figure 2. Strong significant positive relationships were observed between responses in acute $p g c-1 \alpha$ mRNA and SDH activity (MID-POST and PRE-POST, $p<0.01$ ) and glycogen content (MID-POST, $p<0.05$ ). There were no additional significant relationships between responses in acute $p g c-1 \alpha$ mRNA and chronic skeletal muscle adaptations (Table 3). Additionally, linear regressions did not reveal significant relationships between acute responses in vegfa, $s d h a, g p d 1$, and gpd2 mRNA expression and training-induced adaptations in capillary density, and SDH and GPD activity, respectively (Table 4). Acute alterations in $p g c-1 \alpha$, vegfa, $s d h a$, and $g p d 1 / 2 \mathrm{mRNA}$ expression did not relate to individual changes in $\mathrm{VO}_{2}$ peak following two or six weeks of SIT (all $p>0.05$ ). Additionally, aside from significant relationships between individual changes in fibre specific IMTG content and $\mathrm{VO}_{2}$ peak from MID to POST (type I and $\mathrm{VO}_{2}$ peak: $\mathrm{r}=0.62, p<0.05$; type IIA and $\mathrm{VO}_{2}$ peak: $\mathrm{r}=$ $0.58, p<0.05$ ) no other chronic skeletal adaptations (i.e. SDH/GPD activity, glycogen content, capillary density, fibre type composition, and CSA) correlated with changes in $\mathrm{VO}_{2}$ peak (all $p>$ $0.05)$.

Responses to Acute SIT

In response to an acute bout of SIT, $p g c-1 \alpha$ and vegfa mRNA expression significantly

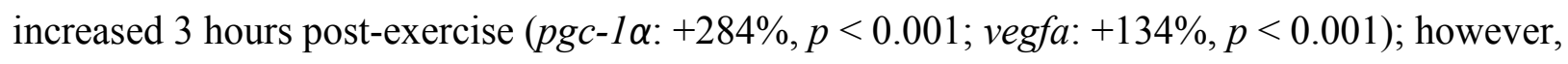


$s d h a, g p d 1$, and $g p d 2$ were unaltered (Figure $3 \mathrm{~A}$ ). Linear regressions performed on individual changes in $p g c-1 \alpha$ and vegfa, sdha, gpdl, and $g p d 2$ mRNA expression revealed a significant positive relationship between the responses in $p g c-1 \alpha$ and vegfa mRNA expression to acute SIT (Figure 3B). No other relationships were significant (data not shown).

\section{Responses to Exercise Training}

Representative slides from an individual participant for all immunofluorescent and histochemical analysis are presented in Figure 4. All analysis on skeletal muscle adaptations to SIT was performed on raw individual data and is presented in Table 5. A main effect of training $(p<0.05)$ was observed for fibre type specific SDH activity, glycogen content, and GPD activity. Additionally, main effects of training were also observed for total estimates of SDH activity, glycogen content, capillary density, and total CSA. Main effects of fibre type $(p<0.05)$ were observed whereby SDH activity and IMTG content was higher in type I fibers whereas GPD activity and glycogen content was higher in type IIA fibres. Additionally, a main effect of fibre type $(p<0.05)$ was observed whereby more type IIA fibres were present than type I fibres in skeletal muscle cross-sections.

For ease of viewing, only the post hoc analysis and group/individual responses at MID and POST expressed relative to PRE are presented in Figure 5 and 6. SDH activity (Figure 5A), capillary density (Figure 6B), and total CSA (Figure 6C) increased at POST compared to PRE and MID (Figure 5A), whereas glycogen content increased at MID and remained elevated without increasing further at POST (Figure 5C). Conversely, GPD activity decreased at POST compared to PRE and MID (Figure 5B).

\section{Discussion}

The current study was designed to test the hypothesis that acute changes in mRNA 
expression predict the magnitude of training induced adaptations in molecular and morphological characteristics of skeletal muscle. The major novel findings of the current study are: 1) acute responses in $p g c-1 \alpha$ mRNA expression correlated with training-induced changes in SDH activity and, to a lesser degree, muscle glycogen content, 2) acute changes in pgc-1 $\alpha$ did not predict changes in the other molecular and morphological variables examined, 3) acute changes in vegfa, $s d h a, g p d 1$ and gpd2 mRNA did not predict changes in capillary density, SDH and/or GPD activity respectively, and 4) individual changes in $p g c-1 \alpha$ and vegfa mRNA correlated following acute SIT, suggesting a coordinated upregulation of gene expression of $p g c-1 \alpha$ and some of its targets.

Relationship Between Acute Responses in pgc-1 $\alpha$ mRNA Expression and Training Induced

\section{Skeletal Muscle Adaptation}

Increases in $p g c-1 \alpha$ mRNA following acute exercise are accompanied by elevations in mRNA expression of many mitochondrial, transcription-regulating and angiogenic genes (Pilegaard et al. 2003, Hellsten et al. 2007, Perry et al. 2010, Iversen et al. 2011, Little et al. 2011). This upregulation of gene expression is proposed to represent the initial phase of traininginduced skeletal muscle adaptations (Hood 2001, Flück and Hoppeler 2003, Flück 2006, Egan and Zierath 2013, Camera et al. 2016). In support of this theory, several studies have demonstrated that acute increases in gene expression, including $p g c-1 \alpha$ expression, precede training-induced increases in mitochondrial protein content/maximal enzyme activity (Perry et al. 2010, Little et al. 2011, Cobley et al. 2012, Serpiello et al. 2012, Egan et al. 2013). Further supporting an important role for the acute upregulation of $p g c-1 \alpha$ in the subsequent adaptive response to training is our observation that increases in $p g c-1 \alpha$ mRNA following a single bout of SIT positively correlated with increases in SDH activity, a marker of skeletal muscle oxidative 
capacity, observed from MID to POST and from PRE to POST. Additionally, acute increases in pgc-1 $\alpha$ mRNA positively related to individual changes in glycogen content from MID to POST, but not PRE to POST. While these results suggest that the ability of skeletal muscle to upregulate pgc-1 $\alpha$ following a single bout of exercise may reflect the overall ability of that muscle to subsequently adapt to training (Hood 2001, Flück and Hoppeler 2003, Flück 2006, Egan and Zierath 2013, Camera et al. 2016), whether this potential predictive relationship persists when analyzing other markers of mitochondrial oxidative capacity, such as mitochondrial protein content and respiration rates, remains an important area for future research. Moreover, the potential to predict training-induced skeletal muscle adaptations by evaluating acute mRNA responses should be validated in future studies with larger sample sizes.

Interestingly, acute increases in $p g c-1 \alpha$ mRNA did not predict individual changes in GPD activity, IMTG content, and fibre type composition following training. While the role of PGC-1 $\alpha$ in regulating these training-induced adaptations is not clear or unequivocal (Lin et al. 2002, Benton et al. 2008, 2010, Choi et al. 2008, Geng et al. 2010), PGC-1 $\alpha$ appears to be necessary for training-induced angiogenesis (Chinsomboon et al. 2009, Leick et al. 2009, Geng et al. 2010). However, acute increases in $p g c-1 \alpha$ mRNA did not predict subsequent training-induced increases in capillary density. Therefore, although acute changes in $p g c-1 \alpha$ mRNA expression predicted chronic adaptation in the activity of a single enzyme (i.e. pgc-1a and SDH), it is unlikely that acute changes in a single gene will predict training-induced changes of complex molecular (e.g. fatty acid uptake and storage) or morphological (e.g. angiogenesis) adaptations that involve the induction of many factors and signalling pathways (Prior et al. 2004, Russell 2004).

Alternatively, while the current study used acute increases in $p g c-1 a$ mRNA to predict skeletal muscle molecular and morphological changes following training, other surrogate markers of 
PGC-1 $\alpha$ activity that increase following one bout of exercise, such as its subcellular localization (Little et al. 2011, Safdar et al. 2011), deacetylation (Gurd 2011), or DNA binding activity of its targeted transcription factors (Wright et al. 2007, Safdar et al. 2011) may better predict traininginduced adaptations. However, the current inability to directly measure PGC-1 $\alpha$ activity in human skeletal muscle may limit the potential to predict all PGC-1 $\alpha$-mediated training-induced adaptations. Collectively, these findings suggest that acute increases in $p g c-1 \alpha \mathrm{mRNA}$ following one session of SIT potentially reflects subsequent adaptations in oxidative capacity but does not necessarily represent the initiation of other chronic SIT-induced skeletal muscle adaptations in recreationally active males. Additionally, PGC-1 $\alpha$ plays an important role in mediating additional exercise-induced skeletal muscle responses such as autophagy and mitophagy (Vainshtein et al. 2015) as well as the unfolded protein response (Wu et al. 2011); an intracellular signalling pathway that improves the capacity of the endoplasmic reticulum to fold and process proteins by increasing production of molecular protein-handling chaperones (Ron and Walter 2007). Therefore, whether exercise-induced increases in $p g c-1 \alpha$ mRNA relates to individual changes in markers of additional PGC-1 $\alpha$-mediated skeletal muscle responses, beyond mitochondrial biogenesis and angiogenesis, remains an important area for future research. Acute Changes in vegfa, sdha, gpd1, and gpd 2 mRNA Expression do not Predict Training Induced Adaptations in Capillary Density and Enzyme Activity

While others have demonstrated that acute increases in angiogenic and mitochondrial mRNA precede training-induced increases in capillary density (Hoier et al. 2012) and mitochondrial protein content/maximal enzyme activity (Perry et al. 2010), we failed to observe a relationship between acute changes in vegfa, $s d h a, g p d 1$, and gpd2 mRNA and chronic changes in the molecular/morphological characteristics of skeletal muscle. Specifically, despite serving as 
a key regulator of skeletal muscle angiogenesis (Olfert et al. 2009, Hoier and Hellsten 2014) acute increases in vegfa mRNA did not predict training-induced increases in capillary density. Additionally, while SDH activity is carried out by subunit A (Ghezzi et al. 2009), sdha mRNA expression was unaltered after acute exercise and did not predict chronic increases in SDH activity following training. Similarly, cytosolic and mitochondrial $\operatorname{gpd}(\operatorname{gpd} 1$ and $g p d 2$, respectively) mRNA failed to increase 3 hours following exercise and individual changes in their mRNA did not predict individual changes in GPD activity following training.

While these results appear inconsistent with the contention that acute increases in mRNA facilitate subsequent training-induced cellular adaptations (Pilegaard et al. 2000, Flück and Hoppeler 2003, Flück 2006, Egan and Zierath 2013), limitations with the current work make this a difficult conclusion to support. Firstly, similar to the limitations in linking acute changes in $p g c-1 a$ to complex molecular/morphological adaptations, perhaps relating acute responses in $v e g f a$ mRNA to training-induced changes in capillary density underappreciates the complexity of the adaptive response underlying angiogenesis (Prior et al. 2004). Secondly, there is evidence that mitochondrial mRNA expression 3 hours following one bout of exercise can both increase (Little et al. 2011, Cobley et al. 2012, Stepto et al. 2012) or remain unaltered (Nordsborg et al. 2010, Stepto et al. 2012), and additional evidence that the increase in some mitochondrial mRNA may be delayed by as much as 24 hours (Cartoni et al. 2005, Perry et al. 2010). Therefore, it is possible that acute changes in vegfa, sdha, and $g p d 1 / 2$ mRNA do predict the adaptive response to training, but that the predictive increases in mRNA expression occurs later than 3 hours post exercise (Edgett et al. 2016). However, despite $s d h a$ mRNA remaining unaltered following a single bout of endurance exercise (Gidlund et al. 2015), to our knowledge this is the first study to measure $s d h a$ and $g p d 1 / 2$ mRNA expression in response to acute SIT in human skeletal muscle. 
Therefore, whether $s d h a$ and gpdl/2 gene expression increases at later time points post SIT remains unknown. Overall, while our results suggest that individual acute responses in vegfa, $s d h a$, and $g p d 1 / 2$ mRNA do not predict training-induced alterations in capillary density and enzyme activity, the limitations associated with our study highlight the importance for future studies to investigate alternative angiogenic and mitochondrial/cytosolic genes at both 3 hours and/or later time points post-exercise. Additionally, while SIT was utilized in the present study, it is unknown whether acute changes in vegfa, sdha, and $g p d 1 / 2$ following a single bout of high intensity interval training (HIIT) or continuous endurance exercise can potentially predict chronic adaptations.

Acute Changes in pgc-1 a and vegfa mRNA are Coordinated

An interesting finding of the present study is that individual changes in $p g c-1 a$ and $v e g f a$ mRNA expression were significantly correlated 3 hours following one bout of SIT. While SIT is known to concomitantly increase $p g c-1 a$ and vegfa gene expression (Taylor et al. 2015), to our knowledge this is the first study to demonstrate a positive significant relationship between individual responses. Evidence from animal models suggest that PGC-1 $\alpha$ mediates, at least in part, vegfa mRNA expression in response to acute exercise (Leick et al. 2009), likely through activation of the nuclear receptor estrogen-related receptor alpha (ERR $\alpha$ ) (Arany et al. 2008). Therefore, the positive association observed in the present study suggests a coordinated upregulation in mRNA expression of $p g c-1 a$ and some of its targets following acute exercise, however, acute increases $p g c-1 \alpha$ did not relate to individual responses in $s d h a$ or $g p d 1 / 2$ mRNA. Interestingly, a recent microarray analysis demonstrated a reduction in $s d h a$ gene expression in PGC-1 $\alpha$ knockout mice (Hatazawa et al. 2016), a result that suggests PGC-1 $\alpha$ regulates $s d h a$ expression, likely through co-activating the transcription factor nuclear respiratory factor-1 
(NRF-1) (Piantadosi and Suliman 2008). There is also limited evidence that PGC-1 $\alpha$ may regulate $g p d 1 / 2$ mRNA expression through its interaction with transcription factors PPAR $\alpha / P P A R \gamma$ (Patsouris et al. 2004, Lin et al. 2005, Krishnan et al. 2009). Therefore, the lack of a relationship between changes in acute $p g c-1 a$ and $s d h a$ and $g p d 1 / 2$ mRNA may either suggest that not all targets of PGC-1 $\alpha$ were upregulated in concert, a result which potentially highlights an underappreciated complexity of the mechanisms associated with activation of PGC-1 $\alpha$ 's downstream targets (Olesen et al. 2010, Scarpulla et al. 2012), or suggests that PGC$1 \alpha$ does not directly regulate $s d h a$ and $g p d l / 2$ mRNA expression in response to acute SIT in human skeletal muscle. Alternatively, the present observation that pgc-1a mRNA only correlated with vegfa mRNA, combined with previous demonstrations that some PGC-1 $\alpha$ targets are not upregulated until $\sim 24$ hours post-exercise (Cartoni et al. 2005, Perry et al. 2010), suggests that alternative mechanisms that are activated later in the recovery period following acute exercise are responsible for the upregulation of these genes. Future investigations should investigate other regulatory mechanisms controlling acute alterations in mRNA expression of PGC- $1 \alpha$ 's targets and determine whether these mechanisms elicit a coordinated upregulation of gene expression.

\section{Conclusion}

This is the first study to examine whether acute changes in mRNA expression predict chronic adaptations to training in human skeletal muscle. A major conclusion from the present findings is that an individual's response in $p g c-1 a$ mRNA following an acute bout of exercise prior to the implementation of a training protocol strongly relates to the degree of traininginduced adaptation in skeletal muscle oxidative capacity (i.e. SDH activity) and glycogen content. Conversely, it appears that chronic changes in enzyme activity (i.e. SDH and GPD) cannot be predicted by acute responses in that enzyme's mRNA expression. Additionally, acute 
increases in gene expression of proteins involved in regulating complex morphological adaptations (i.e. pgc-1 $a$ and vegfa) lack the ability to predict training-induced changes in these morphological characteristics of skeletal muscle (i.e. fibre type composition and angiogenesis). Whether acute mRNA responses of alternative genes that were not examined in the present study predict training-induced skeletal muscle adaptations remains an important area for future research. Furthermore, positive correlations between individual changes in acute $p g c-1 a$ and vegfa but not $s d h a$ mRNA suggests that, despite PGC-1 $\alpha$ co-activating its own promoter via an autoregulatory loop (Handschin et al. 2003), using pgc-1 a mRNA expression to represent PGC$1 \alpha$ activity may not be sensitive enough to capture alterations in all of its targeted genes. Therefore, future investigations should determine whether activation of PGC-1 $\alpha$ induces a coordinated upregulation of additional targeted genes involved in initiating the adaptive response to exercise. Furthermore, positive correlations between individual changes in $p g c-1 a$ and vegfa but not $s d h a$ or gpdl/2 mRNA potentially highlights the complexity of PGC-1 $\alpha$-mediated regulation of mRNA expression following an acute bout of exercise. Lastly, emerging evidence demonstrates that distinct PGC-1 $\alpha$ isoforms are exercise sensitive (Ydfors et al. 2013, Gidlund et al. 2015, Silvennoinen et al. 2015) and regulate different transcriptional programs (MartínezRedondo et al. 2016), which ultimately further perpetuates the complexity of PGC-1 $\alpha$-mediated regulation of mRNA expression in human skeletal muscle.

\section{Conflict of Interest Statement}

The authors declare that there are no conflicts of interest associated with this manuscript.

\section{Acknowledgements}

The authors would like to thank Elizabeth Mathew and a dedicated group of volunteers 
for their help in conducting training sessions. 


\section{References}

Arany, Z., Foo, S.-Y., Ma, Y., Ruas, J.L., Bommi-Reddy, A., Girnun, G., Cooper, M., Laznik, D., Chinsomboon, J., Rangwala, S.M., Baek, K.H., Rosenzweig, A., and Spiegelman, B.M. 2008. HIF-independent regulation of VEGF and angiogenesis by the transcriptional coactivator PGC-1alpha. Nature 451(7181): 1008-12. doi:10.1038/nature06613.

Benton, C.R., Holloway, G.P., Han, X.X., Yoshida, Y., Snook, L.A., Lally, J., Glatz, J.F.C., Luiken, J.J.F.P., Chabowski, A., and Bonen, A. 2010. Increased levels of peroxisome proliferator-activated receptor gamma, coactivator 1 alpha (PGC-1 $\alpha)$ improve lipid utilisation, insulin signalling and glucose transport in skeletal muscle of lean and insulinresistant obese Zucker rats. Diabetologia 53(9): 2008-2019. doi:10.1007/s00125-010-17731.

Benton, C.R., Nickerson, J.G., Lally, J., Han, X.X., Holloway, G.P., Glatz, J.F.C., Luiken, J.J.F.P., Graham, T.E., Heikkila, J.J., and Bonen, A. 2008. Modest PGC-1 $\alpha$ overexpression in muscle in vivo is sufficient to increase insulin sensitivity and palmitate oxidation in subsarcolemmal, not intermyofibrillar, mitochondria. J. Biol. Chem. 283(7): 4228-4240. doi:10.1074/jbc.M704332200.

Bloemberg, D., and Quadrilatero, J. 2012. Rapid determination of myosin heavy chain expression in rat, mouse, and human skeletal muscle using multicolor immunofluorescence analysis. PLoS One 7(4). doi:10.1371/journal.pone.0035273.

Burgomaster, K.A., Heigenhauser, G.J.F., Gibala, M.J., and Kirsten, A. 2006. Effect of shortterm sprint interval training on human skeletal muscle carbohydrate metabolism during exercise and time-trial performance. J. Appl. Physiol. 1: 2041-2047. doi:10.1152/japplphysiol.01220.2005.

Camera, D.M., Smiles, W.J., and Hawley, J.A. 2016. Skeletal Muscle Signaling Pathways and Human Performance. Free Radic. Biol. Med.: 1-13. Elsevier. doi:10.1016/j.freeradbiomed.2016.02.007.

Cartoni, R., Leger, B., Hock, M.B., Praz, M., Crettenand, A., Pich, S., Ziltener, J.L., Luthi, F., Deriaz, O., Zorzano, A., Gobelet, C., Kralli, A., and Russell, A.P. 2005. Mitofusins 1/2 and ERRalpha expression are increased in human skeletal muscle after physical exercise. J Physiol 567(Pt 1): 349-358. doi:10.1113/jphysiol.2005.092031.

Chinsomboon, J., Ruas, J., Gupta, R.K., Thom, R., Shoag, J., Rowe, G.C., Sawada, N., Raghuram, S., and Arany, Z. 2009. The transcriptional coactivator PGC-1alpha mediates exercise-induced angiogenesis in skeletal muscle. Proc. Natl. Acad. Sci. U. S. A. 106(50): 21401-6. doi:10.1073/pnas.0909131106.

Choi, C.S., Befroy, D.E., Codella, R., Kim, S., Reznick, R.M., Hwang, Y.-J., Liu, Z.-X., Lee, H.Y., Distefano, A., Samuel, V.T., Zhang, D., Cline, G.W., Handschin, C., Lin, J., Petersen, 
K.F., Spiegelman, B.M., and Shulman, G.I. 2008. Paradoxical effects of increased expression of PGC-1alpha on muscle mitochondrial function and insulin-stimulated muscle glucose metabolism. Proc. Natl. Acad. Sci. U. S. A. 105(50): 19926-31. doi:10.1073/pnas.0810339105.

Chomcyzynski, P., and Sacchi, N. 1987. Single-step method of RNA isolation by acid guanidinium thiocyanate-. Anal. Biochem. 162(1): 156-159. doi:10.1006/abio.1987.9999.

Cobley, J.N., Bartlett, J.D., Kayani, A., Murray, S.W., Louhelainen, J., Donovan, T., Waldron, S., Gregson, W., Burniston, J.G., Morton, J.P., and Close, G.L. 2012. PGC-1 $\alpha$ transcriptional response and mitochondrial adaptation to acute exercise is maintained in skeletal muscle of sedentary elderly males. Biogerontology 13(6): 621-631. doi:10.1007/s10522-012-9408-1.

Cocks, M., Shaw, C.S., Shepherd, S.O., Fisher, J.P., Ranasinghe, A., Barker, T.A., and Wagenmakers, A.J.M. 2015. Sprint interval and moderate-intensity continuous training have equal benefits on aerobic capacity, insulin sensitivity, muscle capillarisation and endothelial eNOS/NAD(P)Hoxidase protein ratio in obese men. J. Physiol. 0: 1-15. doi:10.1113/jphysiol.2014.285254.

Cocks, M., Shaw, C.S., Shepherd, S.O., Fisher, J.P., Ranasinghe, A.M., Barker, T.A., Tipton, K.D., and Wagenmakers, A.J.M. 2013. Sprint interval and endurance training are equally effective in increasing muscle microvascular density and eNOS content in sedentary males. J. Physiol. 591(Pt 3): 641-56. doi:10.1113/jphysiol.2012.239566.

Coffey, V.G., Jemiolo, B., Edge, J., Garnham, A.P., Trappe, S.W., and Hawley, J.A. 2009a. Effect of consecutive repeated sprint and resistance exercise bouts on acute adaptive responses in human skeletal muscle. Am. J. Physiol. Regul. Integr. Comp. Physiol. 297(5): R1441-R1451. doi:10.1152/ajpregu.00351.2009.

Coffey, V.G., Pilegaard, H., Garnham, A.P., O’Brien, B.J., and Hawley, J.A. 2009b. Consecutive bouts of diverse contractile activity alter acute responses in human skeletal muscle. J. Appl. Physiol. 106(4): 1187-1197. doi:10.1152/japplphysiol.00166.2012.

Edgett, B.A., Bonafiglia, J.T., Baechler, B.L., Quadrilatero, J., and Gurd, B.J. 2016. The effect of acute and chronic sprint-interval training on LRP130, SIRT3, and PGC-1 $\alpha$ expression in human skeletal muscle. Physiol. Rep. 4(17): e12879. doi:10.14814/phy2.12879.

Edgett, B.A., Foster, W.S., Hankinson, P.B., Simpson, C.A., Little, J.P., Graham, R.B., and Gurd, B.J. 2013. Dissociation of Increases in PGC-1 $\alpha$ and Its Regulators from Exercise Intensity and Muscle Activation Following Acute Exercise. PLoS One 8(8): e71623. doi:10.1371/journal.pone.0071623.

Egan, B., O'Connor, P.L., Zierath, J.R., and O'Gorman, D.J. 2013. Time Course Analysis Reveals Gene-Specific Transcript and Protein Kinetics of Adaptation to Short-Term 
Aerobic Exercise Training in Human Skeletal Muscle. PLoS One 8(9).

doi:10.1371/journal.pone.0074098.

Egan, B., and Zierath, J.R. 2013. Exercise metabolism and the molecular regulation of skeletal muscle adaptation. Cell Metab. 17(2): 162-184. Elsevier Inc. doi:10.1016/j.cmet.2012.12.012.

Esbjörnsson, M.M., Hellsten-Westing, Y.Y., Balsom, P.D.P.D., Sjödin, B.B., and Jansson, E.E. 1993. Muscle fibre type changes with sprint training: effect of training pattern. Acta Physiol. Scand. 149(2): 245-246. doi:10.1111/j.1748-1716.1993.tb09618.x.

Flück, M. 2006. Functional, structural and molecular plasticity of mammalian skeletal muscle in response to exercise stimuli. J. Exp. Biol. 209(Pt 12): 2239-2248. doi:10.1242/jeb.02149.

Flück, M., and Hoppeler, H. 2003. Molecular basis of skeletal muscle plasticity--from gene to form and function. Rev. Physiol. Biochem. Pharmacol. 146: 159-216. doi:10.1007/s10254002-0004-7.

Geng, T., Li, P., Okutsu, M., Yin, X., Kwek, J., Zhang, M., and Yan, Z. 2010. PGC-1alpha plays a functional role in exercise-induced mitochondrial biogenesis and angiogenesis but not fiber-type transformation in mouse skeletal muscle. Am. J. Physiol. Cell Physiol. 298(3): C572-C579. doi:10.1152/ajpcell.00481.2009.

Ghezzi, D., Goffrini, P., Uziel, G., Horvath, R., Klopstock, T., Lochmüller, H., D’Adamo, P., Gasparini, P., Strom, T.M., Prokisch, H., Invernizzi, F., Ferrero, I., and Zeviani, M. 2009. SDHAF1, encoding a LYR complex-II specific assembly factor, is mutated in SDHdefective infantile leukoencephalopathy. Nat. Genet. 41(6): 654-656. doi:10.1038/ng.378.

Gibala, M.J., Little, J.P., van Essen, M., Wilkin, G.P., Burgomaster, K.A., Safdar, A., Raha, S., and Tarnopolsky, M.A. 2006. Short-term sprint interval versus traditional endurance training: similar initial adaptations in human skeletal muscle and exercise performance. J. Physiol. 575(Pt 3): 901-911. doi:10.1113/jphysiol.2006.112094.

Gidlund, E., Ydfors, M., Appel, S., Rundqvist, H., Sundberg, C.J., and Norrbom, J. 2015. Rapidly elevated levels of PGC-1 $\alpha$-b protein in human skeletal muscle after exercise: exploring regulatory factors in a randomized controlled trial. J. Appl. Physiol. 119(4): 374384. doi:10.1152/japplphysiol.01000.2014.

Granata, C., Oliveira, R.S.F., Little, J.P., Renner, K., and Bishop, D.J. 2015. Training intensity modulates changes in PGC-1 and p53 protein content and mitochondrial respiration, but not markers of mitochondrial content in human skeletal muscle. FASEB J. doi:10.1096/fj.15276907.

Gurd, B.J. 2011. Deacetylation of PGC-1 $\alpha$ by SIRT1: importance for skeletal muscle function and exercise-induced mitochondrial biogenesis. Appl. Physiol. Nutr. Metab. 36(5): 589597. doi:10.1139/h11-070. 
Handschin, C.C., Rhee, J.J., Lin, J.J., Tarr, P.T.P.T., and Spiegelman, B.M.B.M. 2003. An autoregulatory loop controls peroxisome proliferator-activated receptor gamma coactivator 1alpha expression in muscle. Pnas 100(12): 7111-7116. doi:10.1073/pnas.1232352100.

Hatazawa, Y., Minami, K., Yoshimura, R., Onishi, T., Manio, M.C., Inoue, K., Sawada, N., Suzuki, O., Miura, S., and Kamei, Y. 2016. Deletion of the transcriptional coactivator PGC1 $\alpha$ in skeletal muscles is associated with reduced expression of genes related to oxidative muscle function. Biochem. Biophys. Res. Commun.: 1-8. Elsevier Ltd. doi:10.1016/j.bbrc.2016.10.133.

Hellsten, Y., Nielsen, J.J., Lykkesfeldt, J., Bruhn, M., Silveira, L., Pilegaard, H., and Bangsbo, J. 2007. Antioxidant supplementation enhances the exercise-induced increase in mitochondrial uncoupling protein 3 and endothelial nitric oxide synthase mRNA content in human skeletal muscle. Free Radic. Biol. Med. 43(3): 353-361. doi:10.1016/j.freeradbiomed.2007.02.029.

Hoier, B., and Hellsten, Y. 2014. Exercise-induced capillary growth in human skeletal muscle and the dynamics of VEGF. Microcirculation 21(4): 301-314. doi:10.1111/micc.12117.

Hoier, B., Nordsborg, N., Andersen, S., Jensen, L., Nybo, L., Bangsbo, J., and Hellsten, Y. 2012. Pro- and anti-angiogenic factors in human skeletal muscle in response to acute exercise and training. J. Physiol. 590(Pt 3): 595-606. doi:10.1113/jphysiol.2011.216135.

Hood, D.A. 2001. Invited Review: contractile activity-induced mitochondrial biogenesis in skeletal muscle. doi:10.1152/japplphysiol.00017.2004.

Iversen, N., Krustrup, P., Rasmussen, H.N., Rasmussen, U.F., Saltin, B., and Pilegaard, H. 2011. Mitochondrial biogenesis and angiogenesis in skeletal muscle of the elderly. Exp. Gerontol. 46(8): 670-678. Elsevier Inc. doi:10.1016/j.exger.2011.03.004.

Krishnan, J., Suter, M., Windak, R., Krebs, T., Felley, A., Montessuit, C., Tokarska-Schlattner, M., Aasum, E., Bogdanova, A., Perriard, E., Perriard, J.C., Larsen, T., Pedrazzini, T., and Krek, W. 2009. Activation of a HIF1 $\alpha$-PPAR $\gamma$ Axis Underlies the Integration of Glycolytic and Lipid Anabolic Pathways in Pathologic Cardiac Hypertrophy. Cell Metab. 9(6): 512524. Elsevier Ltd. doi:10.1016/j.cmet.2009.05.005.

Leick, L., Hellsten, Y., Fentz, J., Lyngby, S.S., Wojtaszewski, J.F.P., Hidalgo, J., and Pilegaard, H. 2009. PGC-1alpha mediates exercise-induced skeletal muscle VEGF expression in mice. Am. J. Physiol. Endocrinol. Metab. 297(38): E92-E103. doi:10.1152/ajpendo.00076.2009.

Lin, J., Handschin, C., and Spiegelman, B.M. 2005. Metabolic control through the PGC-1 family of transcription coactivators. Cell Metab. 1(6): 361-370. doi:10.1016/j.cmet.2005.05.004.

Lin, J., Wu, H., Tarr, P.T., Zhang, C.-Y., Wu, Z., Boss, O., Michael, L.F., Puigserver, P., Isotani, E., Olson, E.N., Lowell, B.B., Bassel-Duby, R., and Spiegelman, B.M. 2002.

Transcriptional co-activator PGC-1 $\alpha$ drives the formation of slow-twitch muscle fibres. Nature 418(6899): 797-801. doi:10.1038/nature00936.1. 
Little, J.P., Safdar, A., Bishop, D., Tarnopolsky, M.A., and Gibala, M.J. 2011. An acute bout of high-intensity interval training increases the nuclear abundance of PGC-1 $\alpha$ and activates mitochondrial biogenesis in human skeletal muscle. Am. J. Physiol. Regul. Integr. Comp. Physiol. 300(6): R1303-R1310. doi:10.1152/ajpregu.00538.2010.

Mahoney, D.J., Parise, G., Melov, S., Safdar, A., and Tarnopolsky, M.A. 2005. Analysis of global mRNA expression in human skeletal muscle during recovery from endurance exercise. FASEB J. 19(11): 1498-500. doi:10.1096/fj.04-3149fje.

Martínez-Redondo, V., Jannig, P.R., Correia, J.C., Ferreira, D.M.S., Cervenka, I., Lindvall, J.M., Sinha, I., Izadi, M., Pettersson-Klein, A.T., Agudelo, L.Z., Gimenez-Cassina, A., Brum, P.C., Dahlman-Wright, K., and Ruas, J.L. 2016. Peroxisome proliferator-activated receptor $\gamma$ coactivator-1 $\alpha$ isoforms selectively regulate multiple splicing events on target genes. J. Biol. Chem. 291(29): 15169-15184. doi:10.1074/jbc.M115.705822.

McPhee, J.S., Williams, A.G., Perez-Schindler, J., Degens, H., Baar, K., and Jones, D.A. 2011. Variability in the magnitude of response of metabolic enzymes reveals patterns of coordinated expression following endurance training in women. Exp. Physiol. 96(7): 699-707. doi:10.1113/expphysiol.2011.057729.

Nordsborg, N.B., Lundby, C., Leick, L., and Pilegaard, H. 2010. Relative workload determines exercise-induced increases in PGC-1 $\alpha$ mRNA. Med. Sci. Sports Exerc. 42(8): 1477-1484. doi:10.1249/MSS.0b013e3181d2d21c.

Olesen, J., Kiilerich, K., and Pilegaard, H. 2010. PGC-1 $\alpha$-mediated adaptations in skeletal muscle. Pflugers Arch. Eur. J. Physiol. 460(1): 153-162. doi:10.1007/s00424-010-0834-0.

Olfert, I.M., Howlett, R.A., Tang, K., Dalton, N.D., Gu, Y., Peterson, K.L., Wagner, P.D., and Breen, E.C. 2009. Muscle-specific VEGF deficiency greatly reduces exercise endurance in mice. J. Physiol. 587(Pt 8): 1755-67. doi:10.1113/jphysiol.2008.164384.

Patsouris, D., Mandard, S., Voshol, P.J., Escher, P., Tan, N.S., Havekes, L.M., Koenig, W., März, W., Tafuri, S., Wahli, W., Müller, M., and Kersten, S. 2004. PPAR $\alpha$ governs glycerol metabolism. J. Clin. Invest. 114(1): 94-103. doi:10.1172/JCI200420468.

Perry, C.G.R., Lally, J., Holloway, G.P., Heigenhauser, G.J.F., Bonen, A., and Spriet, L.L. 2010. Repeated transient mRNA bursts precede increases in transcriptional and mitochondrial proteins during training in human skeletal muscle. J. Physiol. 588(Pt 23): 4795-4810. doi:10.1113/jphysiol.2010.199448.

Piantadosi, C.A., and Suliman, H.B. 2008. Transcriptional regulation of SDHa flavoprotein by nuclear respiratory factor-1 prevents pseudo-hypoxia in aerobic cardiac cells. J. Biol. Chem. 283(16): 10967-10977. doi:10.1074/jbc.M709741200.

Pilegaard, H., Ordway, G.A., Saltin, B., and Neufer, P.D. 2000. Transcriptional regulation of gene expression in human skeletal muscle during recovery from exercise. Am. J. Physiol. 
Endocrinol. Metab. 279(4): E806-14. Available from http://www.ncbi.nlm.nih.gov/pubmed/11001762.

Pilegaard, H., Saltin, B., and Neufer, P.D. 2003. Exercise induces transient transcriptional activation of the PGC-1alpha gene in human skeletal muscle. J. Physiol. 546(Pt 3): 851-8. doi:10.1113/jphysiol.2002.034850.

Prior, B.M., Yang, H.T., and Terjung, R.L. 2004. What makes vessels grow with exercise training? J. Appl. Physiol. 97(3): 1119-1128. doi:10.1152/japplphysiol.00035.2004.

Rasmussen, R. 2001. Quantification on the LightCycler. In Rapid Cycle Real-Time PCR. Edited by S. Meuer, C. Wittwer, and K.-I. Nakagawara. Springer Berlin Heidelberg, Berlin, Heidelberg. pp. 21-34. doi:10.1007/978-3-642-59524-0.

Ron, D., and Walter, P. 2007. Signal integration in the endoplasmic reticulum unfolded protein response. Nat. Rev. Mol. Cell Biol. 8(7): 519-529. doi:10.1038/nrm2199.

Russell, a P. 2004. Lipotoxicity: the obese and endurance-trained paradox. Int. J. Obes. Relat. Metab. Disord. 28 Suppl 4: S66-S71. doi:10.1038/sj.ijo.0802859.

Safdar, A., Little, J.P., Stokl, A.J., Hettinga, B.P., Akhtar, M., and Tarnopolsky, M. a. 2011. Exercise increases mitochondrial PGC-1 $\alpha$ content and promotes nuclear-mitochondrial cross-talk to coordinate mitochondrial biogenesis. J. Biol. Chem. 286(12): 10605-10617. doi:10.1074/jbc.M110.211466.

Scarpulla, R.C., Vega, R.B., and Kelly, D.P. 2012. Transcriptional integration of mitochondrial biogenesis. Trends Endocrinol. Metab. 23(9): 459-466. Elsevier Ltd.

doi:10.1016/j.tem.2012.06.006.

Schmittgen, T.D., and Livak, K.J. 2008. Analyzing real-time PCR data by the comparative C(T) method. Nat. Protoc. 3(6): 1101-1108. doi:10.1038/nprot.2008.73.

Scribbans, T.D., Edgett, B.A., Vorobej, K., Mitchell, A.S., Joanisse, S.D., Matusiak, J.B.L., Parise, G., Quadrilatero, J., and Gurd, B.J. 2014. Fibre-specific responses to endurance and low volume high intensity interval training: Striking similarities in acute and chronic adaptation. PLoS One 9(6). doi:10.1371/journal.pone.0098119.

Serpiello, F.R., McKenna, M.J., Bishop, D.J., Aughey, R.J., Caldow, M.K., Cameron-Smith, D., and Stepto, N.K. 2012. Repeated sprints alter signaling related to mitochondrial biogenesis in humans. Med. Sci. Sports Exerc. 44(5): 827-834. doi:10.1249/MSS.0b013e318240067e.

Silvennoinen, M., Ahtiainen, J.P., Hulmi, J.J., Pekkala, S., Taipale, R.S., Nindl, B.C., Laine, T., Häkkinen, K., Selänne, H., Kyröläinen, H., and Kainulainen, H. 2015. PGC $\square 1$ isoforms and their target genes are expressed differently in human skeletal muscle following resistance and endurance exercise. Physiol. Rep. 3(10): e12563. 
Stepto, N.K., Benziane, B., Wadley, G.D., Chibalin, A. V., Canny, B.J., Eynon, N., and McConell, G.K. 2012. Short-Term Intensified Cycle Training Alters Acute and Chronic Responses of PGC1 $\alpha$ and Cytochrome C Oxidase IV to Exercise in Human Skeletal Muscle. PLoS One 7(12): 1-11. doi:10.1371/journal.pone.0053080.

Taylor, C.W., Ingham, S.A., and Ferguson, R.A. 2015. Acute and chronic effect of sprint interval training combined with post-exercise blood flow restriction in trained individuals. Exp. Physiol. 1: n/a-n/a. doi:10.1113/EP085293.

Vainshtein, A., Tryon, L.D., Pauly, M., and Hood, D.A. 2015. The role of PGC-1 $\alpha$ during acute exercise-induced autophagy and mitophagy in skeletal muscle. Am. J. Physiol. - Cell Physiol. (12): ajpcell.00380.2014. doi:10.1152/ajpcell.00380.2014.

Vollaard, N.B.J., Constantin-Teodosiu, D., Fredriksson, K., Rooyackers, O., Jansson, E., Greenhaff, P.L., Timmons, J.A., and Sundberg, C.J. 2009. Systematic analysis of adaptations in aerobic capacity and submaximal energy metabolism provides a unique insight into determinants of human aerobic performance. J. Appl. Physiol. 106(5): 14791486. doi:10.1152/japplphysiol.91453.2008.

Wang, L., and Sahlin, K. 2012. The effect of continuous and interval exercise on PGC-1 $\alpha$ and PDK4 mRNA in type I and type II fibres of human skeletal muscle. Acta Physiol. 204(4): 525-532. doi:10.1111/j.1748-1716.2011.02354.x.

Wright, D.C., Han, D.H., Garcia-Roves, P.M., Geiger, P.C., Jones, T.E., and Holloszy, J.O. 2007. Exercise-induced mitochondrial biogenesis begins before the increase in muscle PGC-1?? expression. J. Biol. Chem. 282(1): 194-199. doi:10.1074/jbc.M606116200.

Wu, J., Ruas, J.L., Estall, J.L., Rasbach, K.A., Choi, J.H., Ye, L., Boström, P., Tyra, H.M., Crawford, R.W., Campbell, K.P., Rutkowski, D.T., Kaufman, R.J., and Spiegelman, B.M. 2011. The unfolded protein response mediates adaptation to exercise in skeletal muscle through a PGC-1 $\alpha /$ ATF6 $\alpha$ complex. Cell Metab. 13(2): 160-169. doi:10.1016/j.cmet.2011.01.003.

Ydfors, M., Fischer, H., Mascher, H., Blomstrand, E., Norrbom, J., and Gustafsson, T. 2013. The truncated splice variants, NT-PGC-1 $\alpha$ and PGC- $1 \alpha 4$, increase with both endurance and resistance exercise in human skeletal muscle. Physiol. Rep. 1(6): e00140. doi:10.1002/phy2.140. 
Table 1. Participant Characteristics.

\begin{tabular}{lccc}
\hline & Pre & Mid & Post \\
\cline { 2 - 4 } Age $(\mathrm{yrs})$ & $22.0 \pm 2.5$ & - & - \\
Height $(\mathrm{cm})$ & $177.9 \pm 6.1$ & - & - \\
Body Mass $(\mathrm{kg})$ & $80.5 \pm 18.1$ & $79.6 \pm 4.7$ & $80.7 \pm 4.9$ \\
$\mathrm{VO}_{2}$ peak $(\mathrm{L} / \mathrm{min}) *$ & $3.4 \pm 0.6$ & $3.5 \pm 0.5$ & $3.7 \pm 0.5 \dagger$ \\
$\mathrm{VO}_{2}$ peak $(\mathrm{mL} / \mathrm{min} / \mathrm{kg})^{*}$ & $42.4 \pm 7.7$ & $44.2 \pm 7.9$ & $46.7 \pm 6.5 \dagger$ \\
\hline
\end{tabular}

Values are means $\pm \mathrm{SD}$.

$*$ Significant $(p<0.05)$ main effect of training, $\uparrow$ Significantly $(p<0.05)$ different than PRE. 
Table 2. List of Primer Sequences used for Real-Time PCR.

\begin{tabular}{lcc}
\hline Gene & Forward Primer $\left(5^{\prime}-3^{\prime}\right)$ & Reverse Primer $\left(5^{\prime}-3^{\prime}\right)$ \\
\hline$p g c-1 \alpha$ & CACTTACAAGCCAAACCAACAAC & CAATAGTCTTGTTCTCAAATGGGGA \\
$v e g f a$ & GGGCAGAATCATCACGAAGT & CACACAGGATGGCTTGAAGA \\
$s d h a$ & TTTGATGCAGTGGTGGTAGG & CAGAGCAGCATTGATTCCTC \\
$g p d 1$ & TGAAAGAGCTGATGCAGACAC & CCAGGCCATCACAGAAGC \\
$g p d 2$ & AGCCAAATGTGTTATCAATGCC & CAAGAAGTCCCATGCTCTCTG \\
$t b p$ & AGACGAGTTCCAGCGCAAGG & GCGTAAGGTGGCAGGCTGTT \\
\hline
\end{tabular}


Table 3. Correlations between changes in acute $p g c-1 \alpha$ mRNA expression and skeletal muscle adaptation following 2 and 6 weeks of SIT.

\begin{tabular}{|c|c|c|c|}
\hline & MID-PRE & POST-MID & POST-PRE \\
\hline$\Delta$ Capillary Density $\left(\mathrm{cap} / \mathrm{mm}^{2}\right)$ & $\begin{array}{l}r=0.26 \\
r^{2}=0.07\end{array}$ & $\begin{array}{l}r=0.14 \\
r^{2}=0.02\end{array}$ & $\begin{array}{l}r=-0.06 \\
r^{2}<0.01\end{array}$ \\
\hline$\Delta$ Total SDH Activity (AU) & $\begin{array}{l}r=-0.29 \\
r^{2}=0.08\end{array}$ & $\begin{array}{l}\mathrm{r}=0.79 * * \\
\mathrm{r}^{2}=0.62 * *\end{array}$ & $\begin{array}{l}\mathrm{r}=0.81 * * \\
\mathrm{r}^{2}=0.65 * *\end{array}$ \\
\hline$\Delta$ Total GPD Activity (AU) & $\begin{array}{l}r=-0.28 \\
r^{2}=0.08\end{array}$ & $\begin{array}{l}r=0.06 \\
r^{2}<0.01\end{array}$ & $\begin{array}{l}r=-0.23 \\
r^{2}=0.05\end{array}$ \\
\hline$\Delta$ Total Glycogen Content (AU) & $\begin{array}{l}r=-0.30 \\
r^{2}=0.10\end{array}$ & $\begin{array}{c}r=0.60^{*} \\
r^{2}=0.36^{*}\end{array}$ & $\begin{array}{l}r=0.46 \\
r^{2}=0.21\end{array}$ \\
\hline$\Delta$ Total IMTG Content (AU) & $\begin{array}{l}r=-0.41 \\
r^{2}=0.16\end{array}$ & $\begin{array}{l}r=0.40 \\
r^{2}=0.16\end{array}$ & $\begin{array}{l}r=0.08 \\
r^{2}<0.01\end{array}$ \\
\hline$\Delta$ Type I Fibre Composition ( $\%)$ & $\begin{array}{l}r=-0.50 \\
r^{2}=0.25\end{array}$ & $\begin{array}{l}r=-0.14 \\
r^{2}=0.02\end{array}$ & $\begin{array}{l}r=-0.46 \\
r^{2}=0.21\end{array}$ \\
\hline$\Delta$ Type IIA Fibre Composition ( $\%)$ & $\begin{array}{c}r=0.37 \\
r^{2}=0.14\end{array}$ & $\begin{array}{c}r=0.29 \\
r^{2}=0.08\end{array}$ & $\begin{array}{l}r=-0.12 \\
r^{2}=0.01\end{array}$ \\
\hline$\Delta$ Total CSA (AU) & $\begin{array}{l}r=-0.43 \\
r^{2}=0.19\end{array}$ & $\begin{array}{l}\mathrm{r}=0.17 \\
\mathrm{r}^{2}=0.03\end{array}$ & $\begin{array}{l}r=-0.07 \\
r^{2}<0.01\end{array}$ \\
\hline
\end{tabular}


Table 4. Correlations between changes in acute mRNA expression and skeletal muscle adaptation following two and six weeks of SIT.

mRNA Expression (Fold Change vs. Pre)

MID-PRE

$\begin{array}{ll}\Delta \text { Capillary } & r=-0.21 \\ \text { Density }\left(\mathrm{cap} / \mathrm{mm}^{2}\right) & \mathrm{r}^{2}=0.05\end{array}$

$\Delta$ Total SDH

Activity (AU)

$\triangle$ Total GPD

Activity (AU)

sdha

gpd1

gpd2

POST-MID

$\begin{array}{lc}\Delta \text { Capillary } & \mathrm{r}=0.17 \\ \text { Density }\left(\mathrm{cap} / \mathrm{mm}^{2}\right) & \mathrm{r}^{2}=0.03\end{array}$

$\Delta$ Total SDH

Activity (AU)

$\triangle$ Total GPD

Activity (AU)

$\mathrm{r}=-0.45$

$\mathrm{r}^{2}=0.20$

$\mathrm{r}=-0.20 \quad \mathrm{r}=-0.12$

$r^{2}=0.04 \quad r^{2}=0.01$

POST-PRE

$\Delta$ Capillary

Density (cap/mm²)

$\Delta$ Total SDH

Activity (AU)

$\triangle$ Total GPD

$r=0.02$
$r^{2}<0.01$

$-\quad r^{2}<0.01$

Activity (AU)

$\mathrm{r}=-0.08$

$\mathrm{r}^{2}<0.01$

$$
\begin{aligned}
& r=-0.10 \\
& r^{2}<0.01
\end{aligned}
$$

$$
\mathrm{r}=-0.04 \quad \mathrm{r}=-0.03
$$

$r^{2}<0.01 \quad r^{2}<0.01$

AU, arbitrary units. 
Table 5. Responses in skeletal muscle molecular and morphological adaptations following two and six weeks of SIT.

\begin{tabular}{|c|c|c|c|}
\hline & PRE & MID & POST \\
\hline \multicolumn{4}{|l|}{ SDH Activity (AU)† } \\
\hline Type I Fibres* & $28.7 \pm 5.9$ & $31.1 \pm 4.8$ & $37.8 \pm 5.9$ \\
\hline Type IIA Fibres* & $22.8 \pm 4.8$ & $25.2 \pm 3.8$ & $31.3 \pm 6.2$ \\
\hline Total Estimate* & $143 \pm 45$ & $159 \pm 42$ & $219 \pm 87$ \\
\hline \multicolumn{4}{|l|}{ GPD Activity (AU) $\dagger$} \\
\hline Type I Fibres* & $30.3 \pm 5.0$ & $29.7 \pm 5.4$ & $26.1 \pm 5.0$ \\
\hline Type IIA Fibres* & $41.0 \pm 10.0$ & $42.8 \pm 12.6$ & $36.2 \pm 7.2$ \\
\hline Total Estimate & $196 \pm 71$ & $205 \pm 61$ & $198 \pm 47$ \\
\hline \multicolumn{4}{|l|}{ Glycogen Content $(\mathrm{AU}) \dagger$} \\
\hline Type I Fibres* & $47.9 \pm 10.8$ & $61.6 \pm 13.3$ & $57.8 \pm 8.7$ \\
\hline Type IIA Fibres* & $56.2 \pm 7.9$ & $69.0 \pm 8.7$ & $66.7 \pm 3.7$ \\
\hline Total Estimate* & $286 \pm 83$ & $372 \pm 130$ & $397 \pm 144$ \\
\hline \multicolumn{4}{|l|}{ IMTG Content $(\mathbf{A U}) \dagger$} \\
\hline Type I Fibres & $37.8 \pm 4.8$ & $37.2 \pm 5.1$ & $36.1 \pm 4.4$ \\
\hline Type IIA Fibres & $34.5 \pm 4.4$ & $34 \pm 5.3$ & $32.6 \pm 4.9$ \\
\hline Total Estimate & $200 \pm 61.7$ & $202 \pm 68$ & $216 \pm 79$ \\
\hline \multicolumn{4}{|l|}{ Fibre Type Composition $(\%) \dagger$} \\
\hline Type I Fibres & $52.8 \pm 9.7$ & $51.1 \pm 10.5$ & $47.9 \pm 13.2$ \\
\hline Type IIA Fibres & $39.7 \pm 7.1$ & $42.8 \pm 8.2$ & $48.7 \pm 12.4$ \\
\hline Capillary Density $\left(\mathrm{cap} / \mathrm{mm}^{2}\right)^{*}$ & $375 \pm 65$ & $404 \pm 97$ & $433 \pm 82$ \\
\hline Cross Sectional Area $(\mathrm{AU})^{*}$ & $5383 \pm 1600$ & $5602 \pm 1705$ & $6347 \pm 1849$ \\
\hline
\end{tabular}




\section{Figure Captions}

Figure 1. Timeline of sample collection during acute exercise visit (A) and six weeks of SIT (B).

Figure 2. Relationships between acute responses in $p g c-1 \alpha$ mRNA expression and traininginduced changes in total SDH activity from MID to POST (A; $n=12)$ and PRE to POST (B; $\mathrm{n}=13)$. AU, arbitrary units.

Figure 3. Individual and group mean responses in skeletal muscle mRNA expression of $p g c-1 \alpha$, vegfa, sdha, $g p d 1$, and $g p d 2$ to one session of sprint interval training at 3 hours post-exercise (A). Relationship between acute responses in pgc-1 $\alpha$ and vegfa mRNA (B). $\mathrm{N}=14$.

* Significantly different than PRE, $p<0.001$.

Figure 4. Representative slides from an individual participant for skeletal muscle fibre type composition (blue fibres are type I, green are type IIA), capillary density, SDH and GPD activity, and glycogen and IMTG content at PRE, MID, and POST. Scale bars represent 100 microns $(\mu \mathrm{m})$. Labelled fibres are the same across all images at each time point.

Figure 5. Individual and group mean responses in fibre type specific and total molecular responses to six weeks of sprint-interval training. Responses in SDH (A; n=12) and GPD (B; $\mathrm{n}=13)$ activity, and glycogen $(\mathrm{C} ; \mathrm{n}=13)$, and IMTG $(\mathrm{D} ; \mathrm{n}=13)$ content are presented relative to PRE at MID and POST. Total estimates of molecular responses were determined by the sum of multiplying fibre type specific optical density, composition percentage, and cross-sectional area then dividing by 100000 .

* Significantly different than PRE, $p<0.05$.

$\dagger$ Significantly different than MID, $p<0.05$.

Figure 6. Individual and group mean responses in morphological adaptations to six weeks of 
sprint interval training. Responses in fibre type composition (A), capillary density (B), and total CSA (C) are presented relative to PRE at MID and POST. N=13.

* Significantly different than PRE, $p<0.05$. 


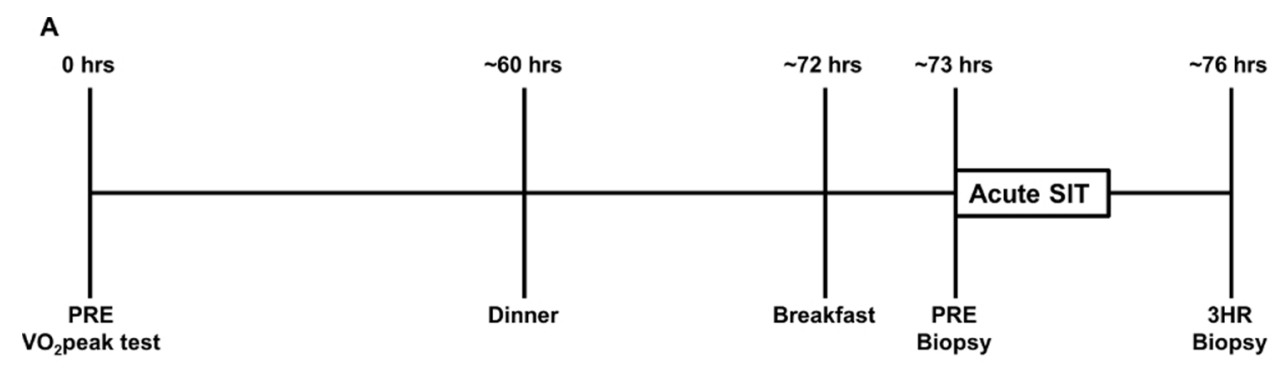

B

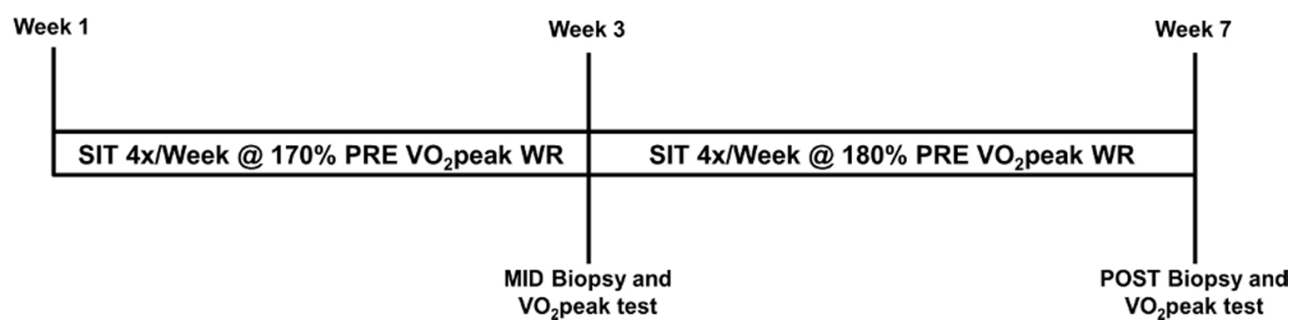

Figure 1. Timeline of sample collection during acute exercise visit (A) and six weeks of SIT (B).

$86 \times 49 \mathrm{~mm}(300 \times 300$ DPI $)$ 


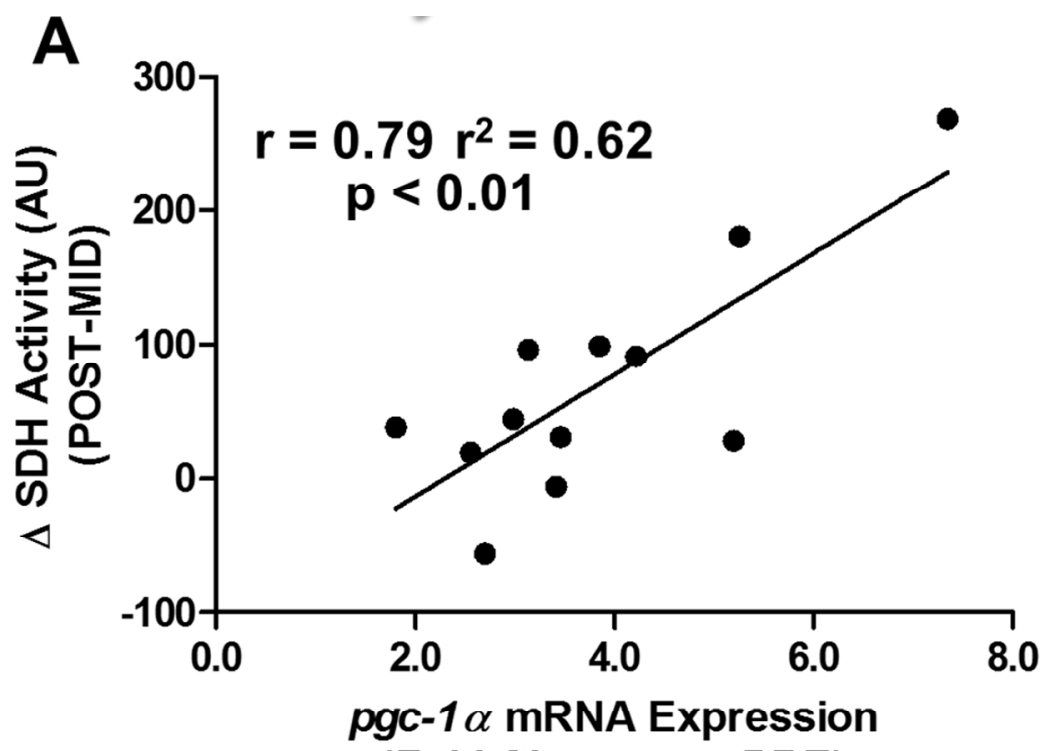

(Fold Change vs. PRE)

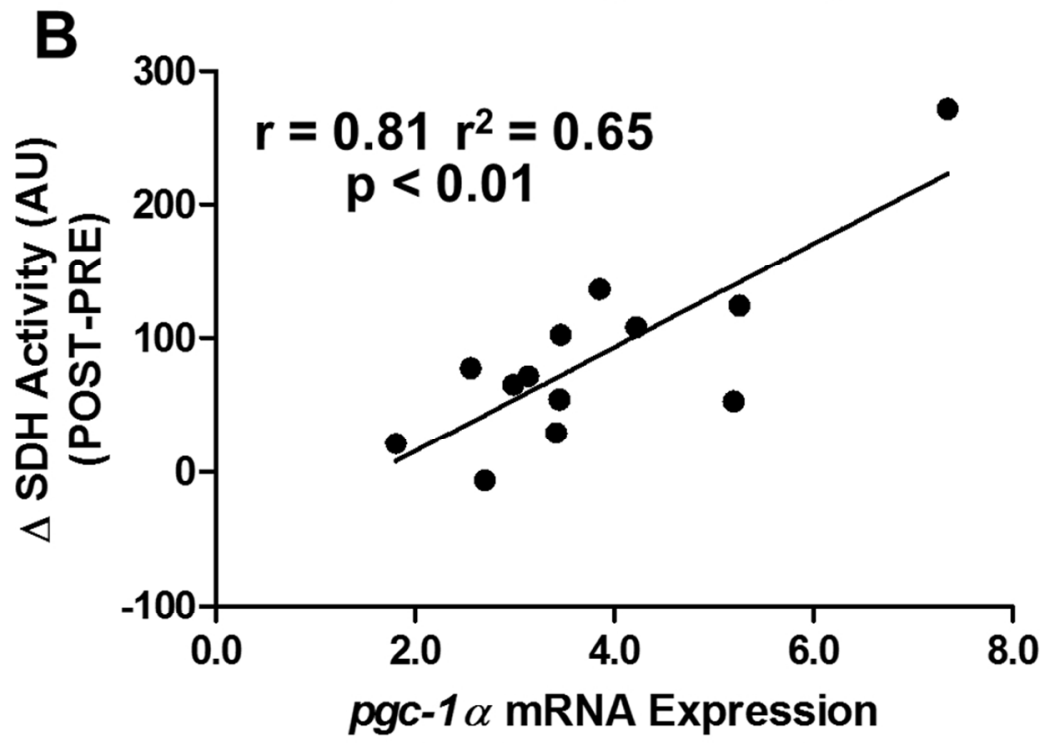

(Fold Change vs. PRE)

Figure 2. Relationships between acute responses in pgc-1a mRNA expression and training-induced changes in total SDH activity from MID to POST (A) and PRE to POST (B). AU, arbitrary units.

$86 \times 131 \mathrm{~mm}(300 \times 300$ DPI $)$ 

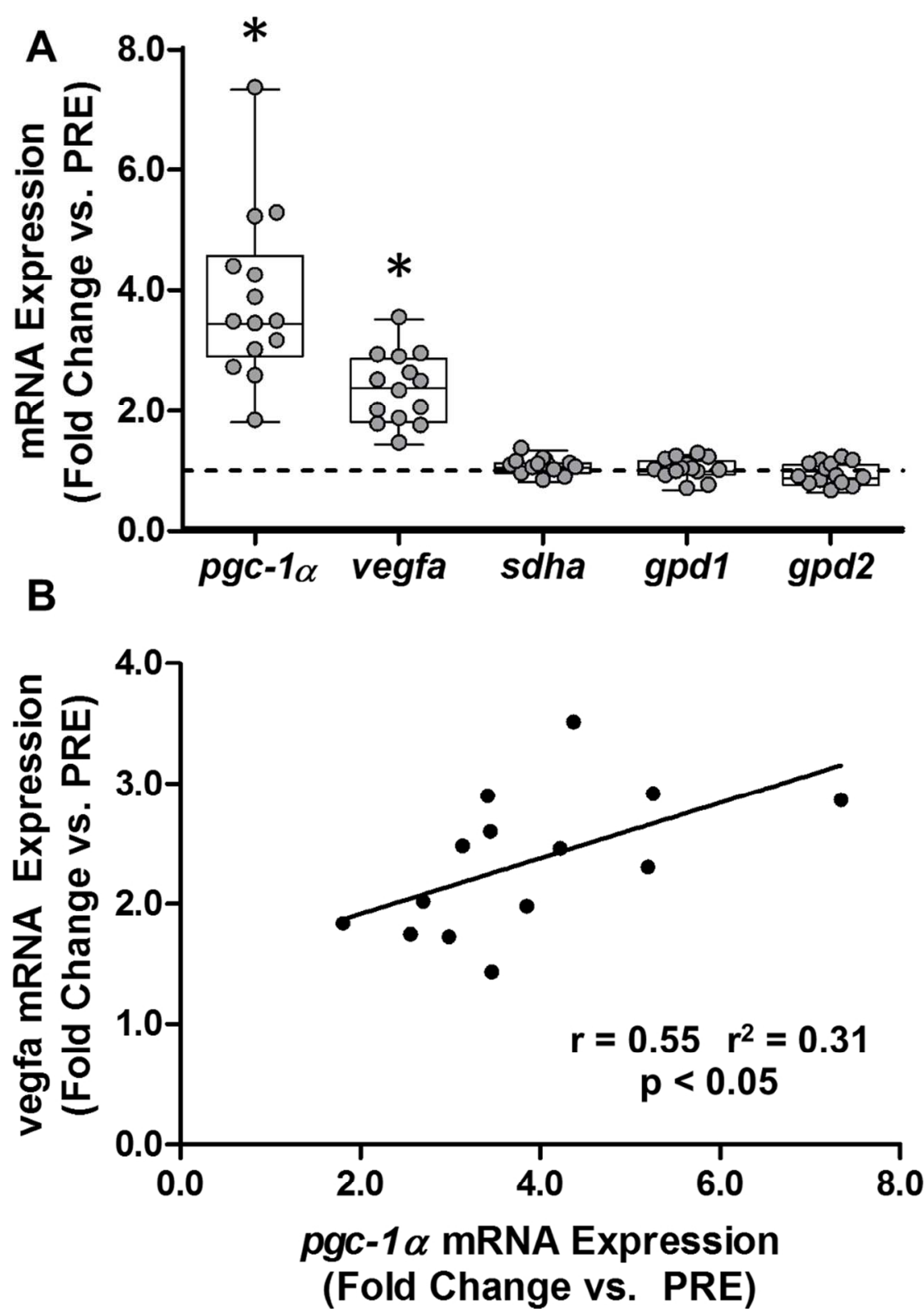

Figure 3. Individual and group mean responses in skeletal muscle mRNA expression of pgc-1a, vegfa, sdha, gpd1, and gpd2 to one session of sprint interval training at 3 hours post-exercise (A). Relationship between acute responses in pgc-1a and vegfa mRNA (B).

* Significantly different than PRE, $\mathrm{p}<0.001$. 

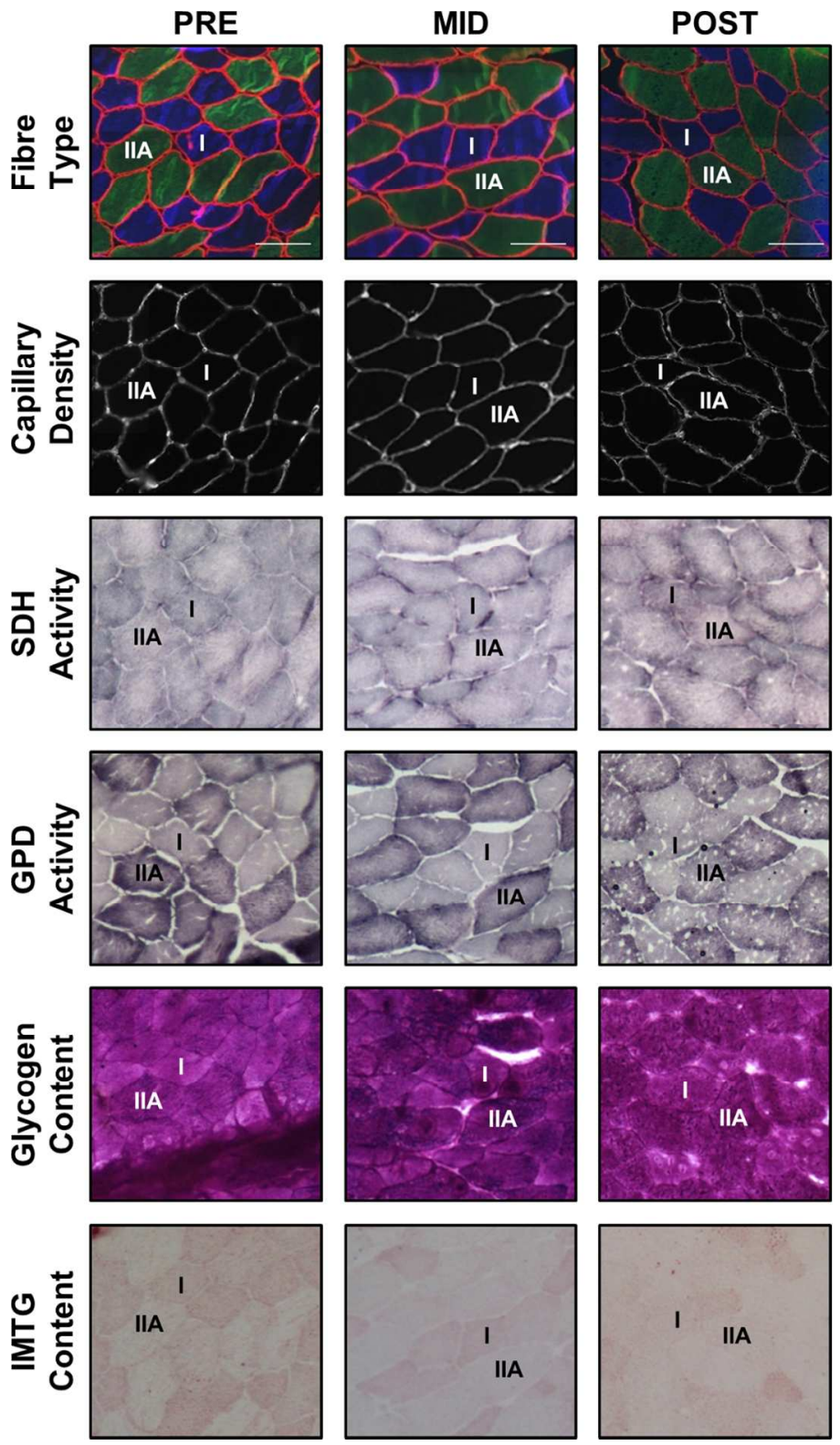

Figure 4. Representative slides from an individual participant for skeletal muscle fibre type composition (blue fibres are type I, green are type IIA), capillary density, SDH and GPD activity, and glycogen and IMTG content at PRE, MID, and POST. Scale bars represent 100 microns $(\mu \mathrm{m})$. Labelled fibres are the same across all images at each time point.

$86 \times 149 \mathrm{~mm}(300 \times 300 \mathrm{DPI})$ 

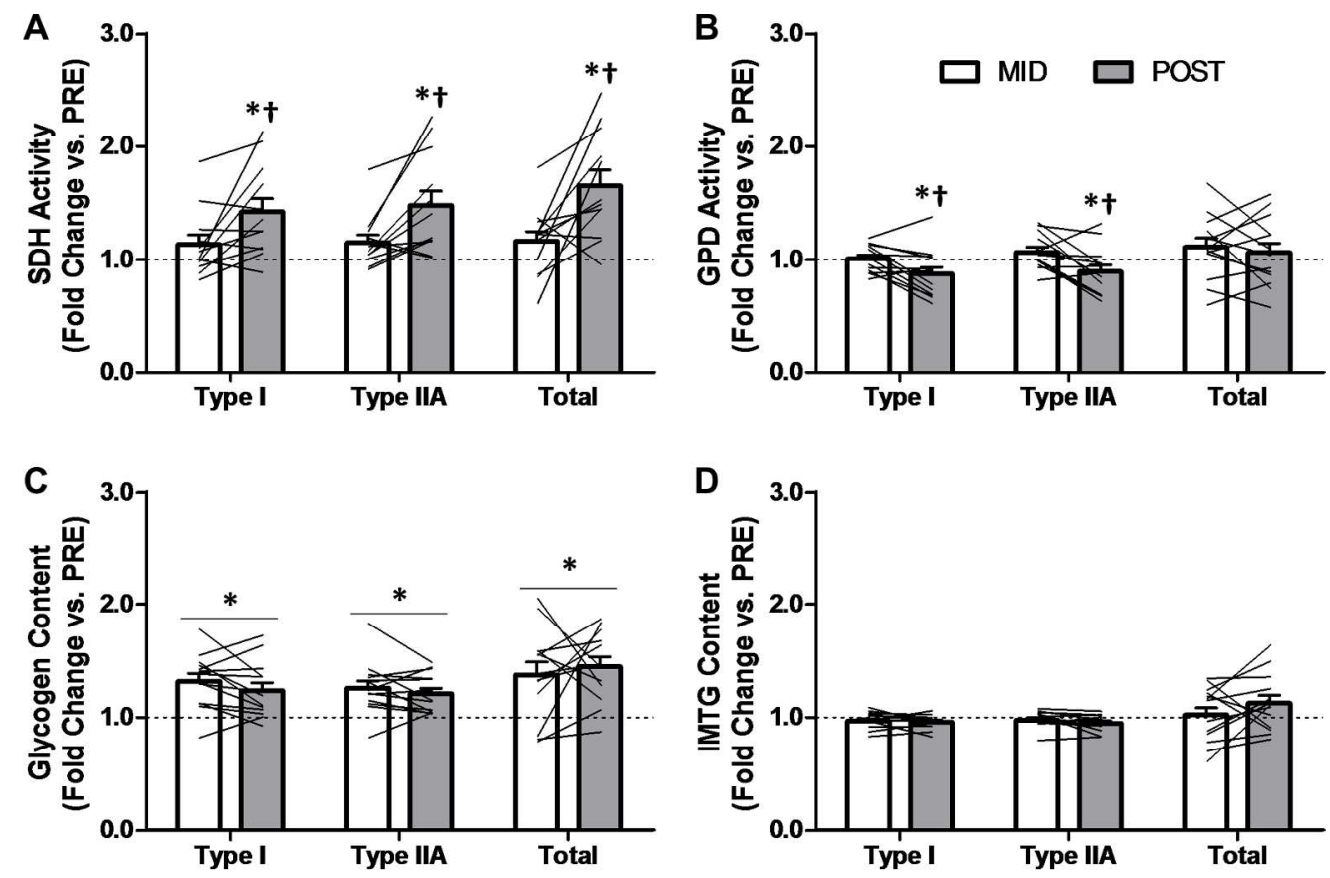

Figure 5. Individual and group mean responses in fibre type specific and total molecular adaptations to six weeks of sprint-interval training. Responses in SDH (A) and GPD (B) activity, and glycogen (C), and IMTG (D) content are presented relative to PRE at MID and POST.

* Significantly different than PRE, $\mathrm{p}<0.05$.

+ Significantly different than MID, $\mathrm{p}<0.05$.

$178 \times 117 \mathrm{~mm}(300 \times 300 \mathrm{DPI})$ 

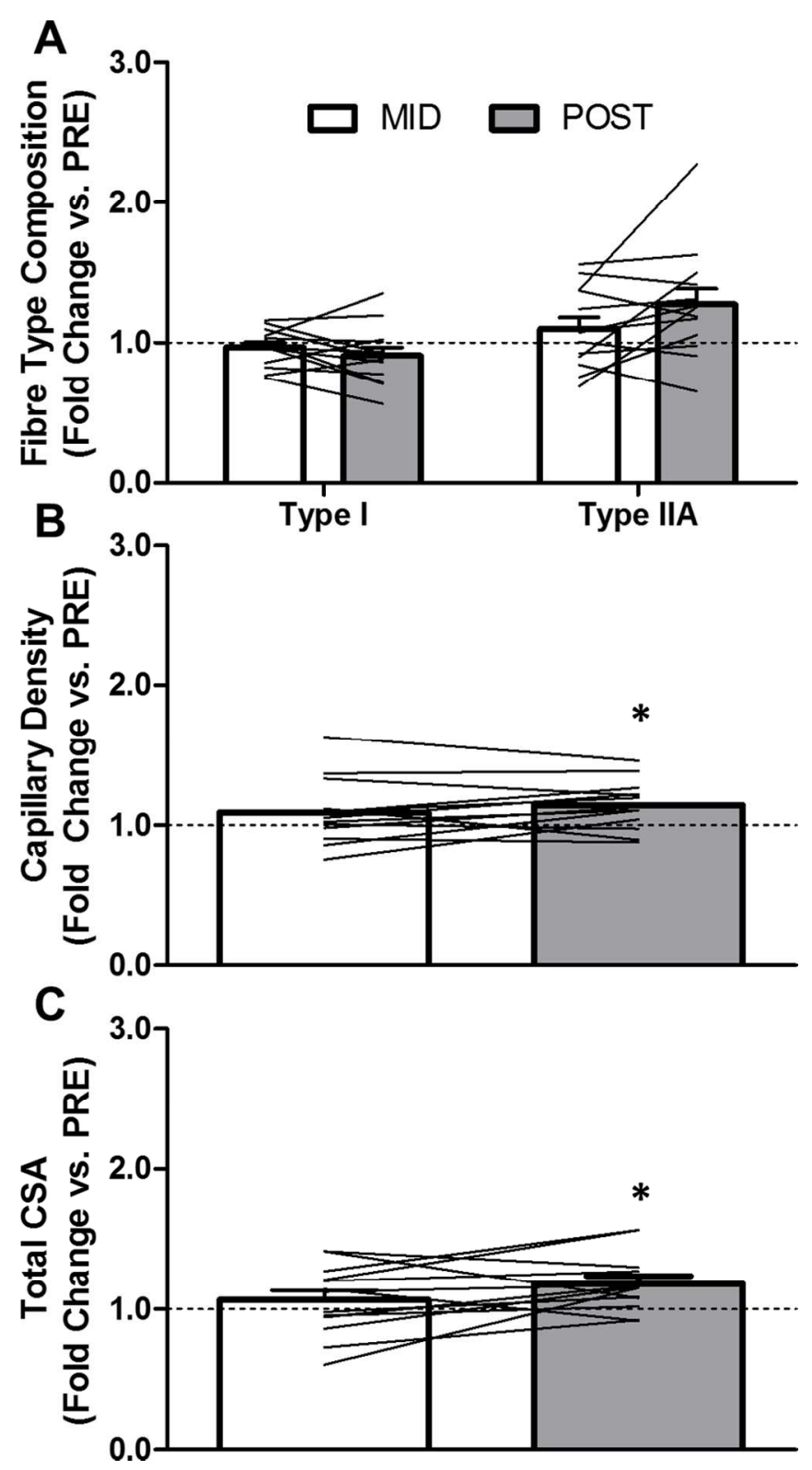

Figure 6. Individual and group mean responses in morphological adaptations to six weeks of sprint interval training. Responses in fibre type composition (A), capillary density (B), and total CSA (C) are presented relative to PRE at MID and POST.

* Significantly different than PRE, $\mathrm{p}<0.05$.

$86 \times 159 \mathrm{~mm}(300 \times 300 \mathrm{DPI})$ 